\title{
Potassium solubilizing bacteria (KSB): Mechanisms, promotion of plant growth, and future prospects - a review
}

\author{
Hassan Etesami ${ }^{*}$, Somayeh Emami ${ }^{1}$, Hossein Ali Alikhani ${ }^{1}$ \\ ${ }^{1}$ Department of Soil Science, Faculty of Agricultural Engineering \& Technology, University College of \\ Agriculture \& Natural Resources, University of Tehran, Karaj-Iran. *Corresponding author: hassanetesami@, \\ ut.ac.ir
}

\begin{abstract}
Potassium $(\mathrm{K})$ is considered as an essential nutrient and a major constituent within all living cells. Naturally, soils contain $\mathrm{K}$ in larger amounts than any other nutrients; however most of the $\mathrm{K}$ is unavailable for plant uptake. Application of chemical fertilizers has a considerably negative impact on environmental sustainability. It is known that potassium solubilizing bacteria (KSB) can solubilize K-bearing minerals and convert the insoluble $\mathrm{K}$ to soluble forms of $\mathrm{K}$ available to plant uptake. Many bacteria such as Acidothiobacillus ferrooxidans, Paenibacillus spp., Bacillus mucilaginosus, B. edaphicus, and B. circulans have capacity to solubilize $\mathrm{K}$ minerals (e.g., biotite, feldspar, illite, muscovite, orthoclase, and mica). KSB are usually present in all soils, although their number, diversity and ability for K solubilization vary depending upon the soil and climatic conditions. KSB can dissolve silicate minerals and release $\mathrm{K}$ through the production of organic and inorganic acids, acidolysis, polysaccharides, complexolysis, chelation, and exchange reactions. Hence, the production and management of biological fertilizers containing KSB can be an effective alternative to chemical fertilizers. This article presents an overview of current trends and challenges on $\mathrm{KSB}$, mechanisms and their role in plant growth promotion, and eventually gives some perspectives for research on $\mathrm{K}$ in agriculture.
\end{abstract}

Keywords: Bio-fertilizer, potassium bearing minerals; potassium solubilization, plant and bacteria interactions, PGPRs 


\section{Introduction}

Feeding a growing world population, as projected to reach 9 billion by 2050, adopting more efficient and sustainable production methods, responding to increased concerns about managing the natural resources, and adapting to climate change and drought conditions in several developing regions (notably in Europe, Central Asia and the Horn of Africa) are some of the significant challenges that agriculture will face in the 21 st century (Haub et al., 2012).

In order to feed the increasing world population, agriculture must be intensive and sustainable in the future. However, it is well known that the food production by agriculture cannot be generally sustained unless the nutrients removed from soil as a result of increased crop production are replaced. Many agricultural soils lack a sufficient amount of one or more of essential plant nutrients so that plant growth is suboptimal. To obviate this problem and obtain higher plant yields, farmers have become increasingly dependent on chemical sources of fertilizers (Glick, 2012). While the chemical fertilizers helped plant grow, they did not improve the properties of soil. It is well known that the constant use of chemical fertilizers, mainly phosphorous, nitrogenous, and potassic fertilizers have harmful effects on the environment (Adesemoye and Kloepper, 2009).

After nitrogen $(\mathrm{N})$ and phosphorus $(\mathrm{P})$, potassium $(\mathrm{K})$ is the most important plant nutrient that has a key role in the growth, metabolism and development of plants. In addition to increasing plant resistance to diseases, pests, and abiotic stresses, $\mathrm{K}$ is required to activate over 80 different enzymes responsible for plant and animal processes. E.g. such as energy metabolism, starch synthesis, nitrate reduction, photosynthesis, and sugar degradation (Almeida et al., 2015; Cecílio Filho et al., 2015; Gallegos-Cedillo et al., 2016; Hussain et al., 2016; White and Karley, 2010; Yang et al., 2015). $\mathrm{K}$ is the seventh most abundant element in Earth's crust. Total $\mathrm{K}$ content in soils ranges between 0.04 and $3 \% \mathrm{~K}$. Although $\mathrm{K}$ is present as an abundant element in soil, only 1 to $2 \%$ of this element is available to plants (Sparks and Huang, 1985). The rest are bound with other minerals and therefore are unavailable to plants. $\mathrm{K}$ is present in several forms in the soil, including mineral $\mathrm{K}$, non-exchangeable $\mathrm{K}$, exchangeable $\mathrm{K}$, and solution $\mathrm{K}$. Interrelationships of various forms of soil $\mathrm{K}$ are shown in Figure 1. Depending on soil type, from 90 to $98 \%$ of soil $\mathrm{K}$ is mineral $\mathrm{K}$ and most of this $\mathrm{K}$ is unavailable for plant uptake (Sparks and Huang, 1985). Minerals containing K are feldspar (orthoclase and microcline) and mica (biotite and muscovite). The non-exchangeable form of $\mathrm{K}$ makes up approximately 1 to $10 \%$ of soil $\mathrm{K}$ and is trapped between the layers or sheets of certain kinds of clay minerals (Sparks, 1987). Solution $\mathrm{K}$ is the form of $\mathrm{K}$ that directly and readily is taken up by plants and microbes in soil. In addition, this form is most subject to leaching in soils. The concentration of soil solution $\mathrm{K}$ varies from 2 to $5 \mathrm{mg} \mathrm{l}^{-1}$ for normal agricultural soils (Sparks and Huang, 1985). The major amounts of $\mathrm{K}$ in the soil is present as a fixed form (non-available to plant indirectly) due to imbalanced fertilizer utilization, great increase of crop yield (depleting soil solution $\mathrm{K}$ ), and the depletion of $\mathrm{K}$ in the soil system. As a result, $\mathrm{K}$ deficiency has been reported in most of the crop plants (Meena et al., 2014; Xiao et al., 2017). Since cost of K-fertilizers (the price of potash $\$ 470$ per ton since 2011) is increasing every year (Meena et al., 2014) and also use of these fertilizers has harmful effects on the environment, it is necessary to find an alternative indigenous source of $\mathrm{K}$ and maintain $\mathrm{K}$ level in soils for sustainable crop production. It has been proven that microbial soil community is able to influence soil fertility through soil processes viz. decomposition, mineralization, and storage / release of nutrients (Parmar and Sindhu, 2013). It has 
been reported that some beneficial soil microorganisms, such as a wide range of saprophytic bacteria, fungal strains and actinomycetes, could solubilize the insoluble $\mathrm{K}$ from soils by various mechanisms. Some of these mechanisms include the production of inorganic and organic acids, acidolysis, polysaccharides, complexolysis, chelation, polysaccharides, and exchange reactions.

Among these microorganisms, $\mathrm{K}$ solubilizing bacteria (KSB) have attracted the attention of agriculturists as soil inoculum to promote the plant growth and yield. The KSB are effective in releasing $\mathrm{K}$ from inorganic and insoluble pools of total soil $\mathrm{K}$ through solubilization (Archana et al., 2013; Gundala et al., 2013; Keshavarz Zarjani et al., 2013; Meena et al., 2014; Meena et al., 2015b; Parmar and Sindhu, 2013; Saha et al.,
2016; Zeng et al., 2012; Zhang et al., 2013). It has been reported that inoculation with KSB produced beneficial effect on growth of different plants (Ahmad et al., 2016; Bakhshandeh et al., 2017; Xiao et al., 2017).

The above studies show that KSB can provide an alternative technology to make $\mathrm{K}$ available for uptake by plants. Thus, identification of efficient bacterial strains capable of solubilizing $\mathrm{K}$ minerals can quickly conserve our existing resources and avoid environmental pollution hazards caused by heavy application of K-fertilizers. Hence, in this review, we elaborated the studies of KSB including isolation and mechanisms of solubilizing K-bearing minerals to develop efficient bacterial inoculants for solubilization of $\mathrm{K}$ in soil, which is one of the aims of achieving sustainable agriculture.

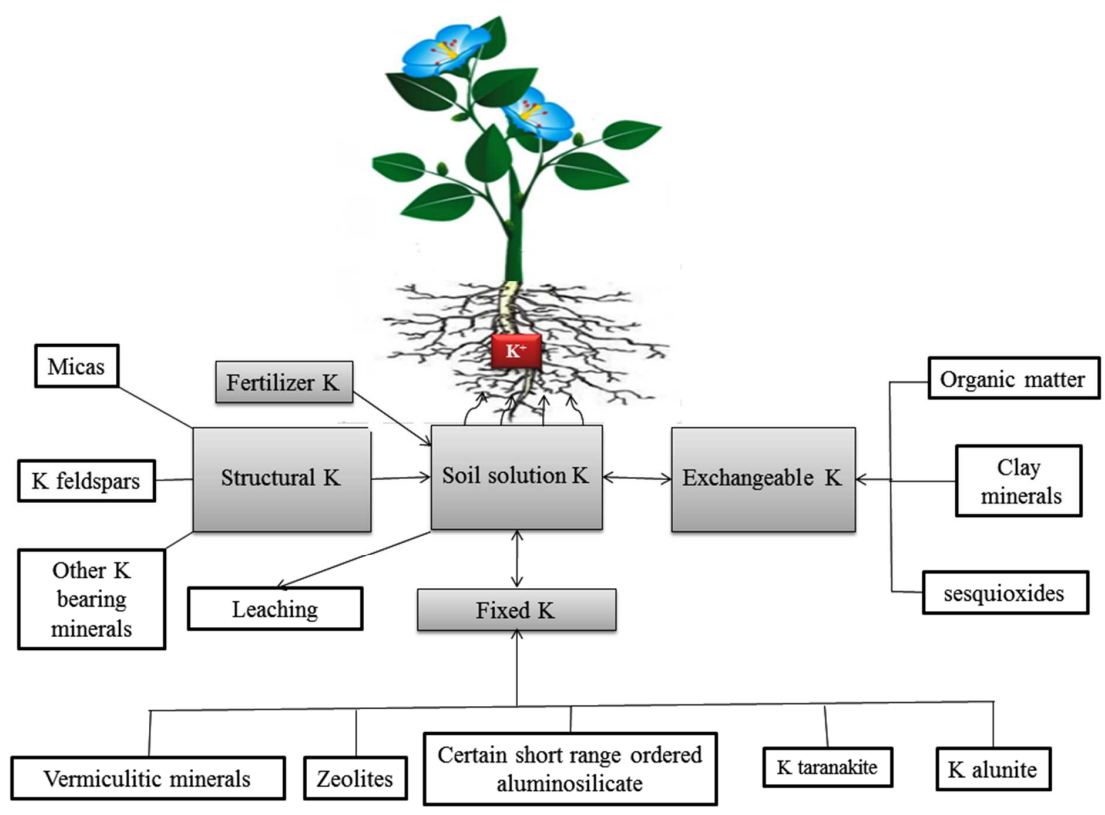

Figure 1. Interrelationships of various forms of soil K (Sparks and Huang, 1985). 


\section{Bacteria-soil-plant interactions}

Soil is a complex mixture of minerals, water, air, organic matter, billions of organisms, and the changes taking place in its composition (biogeochemical transformations). Soil fertility refers to the capacity of the soil to supply essential plant nutrients such as $\mathrm{N}, \mathrm{P}$, $\mathrm{K}$ and micronutrients, which are often not available in free form or are in limited quantities in the soil. This is where root-associated beneficial microbes are important partners (de Zelicourt et al., 2013).

It is known that microorganisms can make nutrients available to plant by different mechanisms (Zhao et $a l ., 2016)$. In the soil, it is possible to find various types of microorganisms such as bacteria, fungi, actinomycetes, protozoa, and algae which bacteria are by far the most common (i.e., 95\%). There is an estimated 60,000 different type of bacteria that reside in the soil, most of which have yet to be even named, and each has its own particular roles and capabilities. The number and diversity of bacteria are influenced by the soil conditions such as organic carbon, temperature, moisture, electrical conductivity and other chemicals as well as by the number and types of plants found in those soils. Therefore, soil-grown plants are immersed in a sea of microorganisms especially bacteria (Glick, 2012).

Recent studies show that most plant species require microbial associations for survival (de Zelicourt et al., 2013; Ma et al., 2016). In addition, plants possess the ability to select their own root microflora from the surrounding soil. In other words, each particular plant species has a characteristic group of associated microbes. The establishment of beneficial plant-microbial interactions needs a mutual recognition and a considerable orchestration of the responses at both the plant and the microbial side (de Zelicourt et al., 2013). By exuding chemicals or signals, plants can effectively communicate with the rhizosphere microorganisms, while their associated microbes may establish an efficient associative symbiosis with plants by triggering host functional signals (e.g., microbial chemotaxis and colonization) (Chaparro et al., 2013; Ma et al., 2016).

The interactions established between bacteria and plant may be beneficial (e.g., plant growth promoting rhizobacteria, PGPRs), harmful (e.g. pathogens), or neutral for the plant, and sometimes the impact of a bacterium may vary as the soil conditions change (Cheng et al., 2010). The bacteria that provide some benefits to plants are: (i) those that form nodules on host plant roots (symbiotic relationship) and fix nitrogen; (ii) those that are endophytic and colonize the internal plant tissues without pathogenic effects in host; (iii) those that have ability to competitively colonize the rhizosphere and plant root surface; and (iv) those that are free living in the soil (Glick, 2012).

In agriculture, beneficial bacteria are defined as any bacteria that colonize the roots of plants following inoculation onto seed and improve plant growth by increasing seed emergence, plant weight, and crop yields. Despite the limited understanding of soil bacteria-plant interactions, a number of these bacteria are used commercially as adjuncts to agricultural practice (Glick, 2012). These bacteria include Burkholderia cepacia, Delfitia acidovorans, Paenibacillus macerans, Pantoea agglomerans, Pseudomonas spp., P. aureofaciens, P. chlororaphis, P. fluorescens, P. solanacearum, Bacillus spp., B. mucilaginous, $B$. pumilus, B. subtilis, B. amyloliquefaciens, B. fimus, B. licheniformis, B. megaterium, Agrobacterium radiobacter, Azospirillum brasilense, A. lipoferum, Azotobacter chroococcum, P. syringae, Serratia entomophilia, Streptomyces spp., S. griseoviridis, and S. lydicus (Glick, 2012).

According to definition mentioned above, KSB are also known as plant growth promoting bacteria (PGPRs) (Gundala et al., 2013). In general, PGPRs help the plant growth by two mechanisms (Glick, 2012): (i) 
direct action mechanisms by either providing plants with resources/nutrients (e.g., N, P, Fe and other essential minerals) or regulating plant hormone levels (cytokinins, gibberellins, indole-3-acetic acid, and ethylene); and (ii) indirect action mechanisms by decreasing the deleterious effects of various pathogens on the growth and yield of plants as bio-control agents. Direct and indirect mechanisms of PGPRs in promoting plant growth and in providing $\mathrm{K}$ to plant are shown in Figure 2.
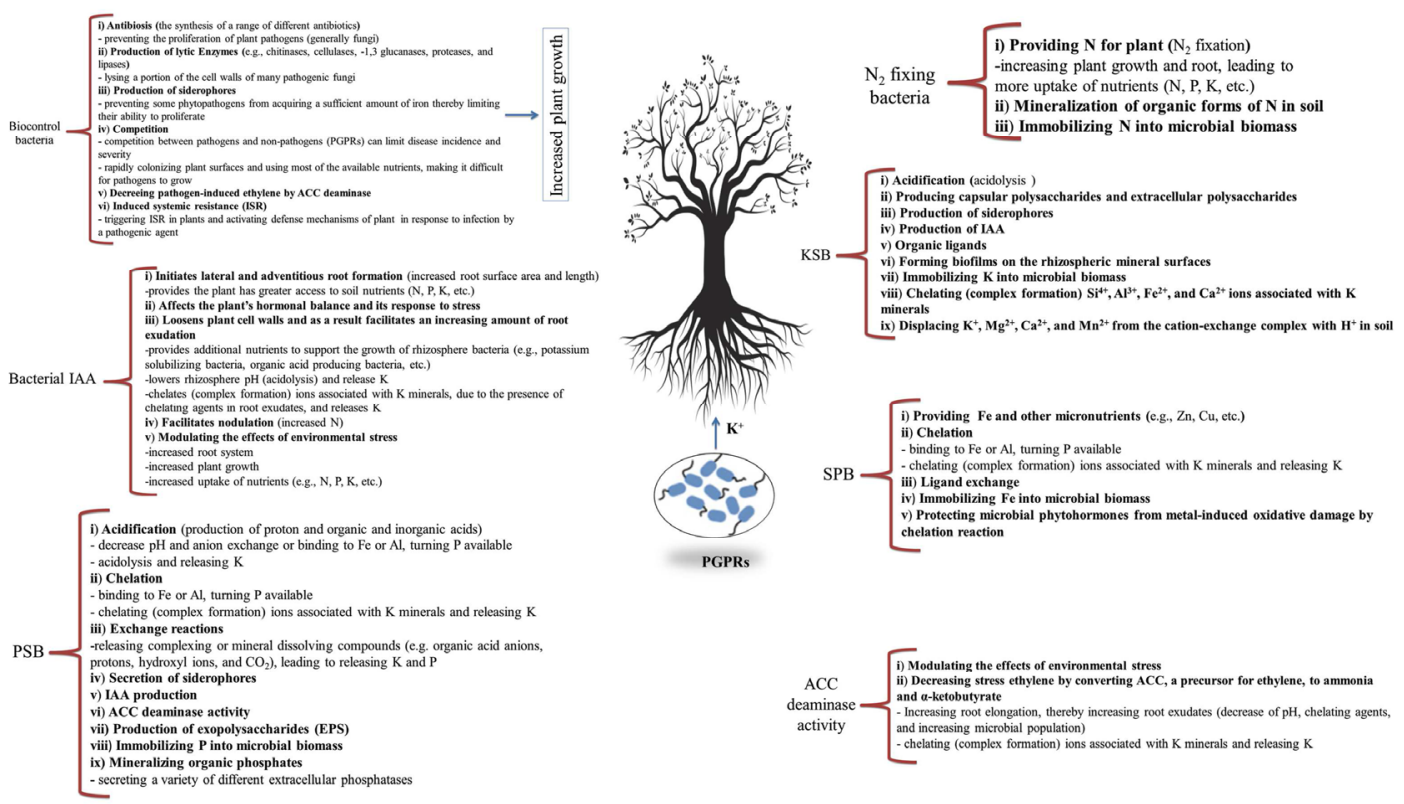

Figure 2. Direct and indirect mechanisms of PGPRs in promoting plant growth and in providing K to plant. IAA, indole-3-acetic acid; PSB, phosphate solubilizing bacteria; ACC, 1-aminocyclopropane-1-carboxylate; KSB, potassium solubilizing bacteria; and SPB, siderophore producing bacteria

\section{Potassium solubilizing bacteria (KSB) and their screening}

$\mathrm{K}$ solubilization is done by a wide range of saprophytic bacteria, fungal strains and actinomycetes (Ahmad et al., 2016; Bakhshandeh et al., 2017; Gundala et al., 2013; Meena et al., 2014). There are strong evidences that soil bacteria are capable of transforming soil $\mathrm{K}$ to the forms available to plant effectively (Meena et al., 2015a; Meena et al., 2014; Meena et al., 2016). There is considerable population of KSB in soil and in plant rhizosphere. These include both aerobic and anaerobic isolates that the most frequently KSB in soil are aerobic. A considerably higher concentration of KSB is commonly found in the rhizosphere in comparison with non-rhizosphere soil (Padma and Sukumar, 2015). Solubilization of K by KSB from insoluble and fixed forms is an import aspect regarding $\mathrm{K}$ availability in soils. The ability to solubilize the silicate rocks by B. mucilaginosus, B. circulanscan, B. edaphicus, 
Burkholderia, A. ferrooxidans, Arthrobacter sp., Enterobacter hormaechei, Paenibacillus mucilaginosus, P. frequentans, Cladosporium, Aminobacter, Sphingomonas, Burkholderia, and Paenibacillus glucanolyticus has been reported (Meena et al., 2016). Among the soil bacterial communities, B. mucilaginosus, $B$. edaphicus and B. circulanscan have been described as effective K solubilizers (Meena et al., 2015a; Meena et al., 2014; Meena et al., 2016). KSB are usually present in all soils and have been isolated from rhizosphere soil, non-rhizosphere soil, paddy soil (Bakhshandeh et al., 2017) and saline soil (Bhattacharya et al., 2016).

$\mathrm{KSB}$ are isolated by serial dilution plate method using modified Aleksandrov medium including $5.0 \mathrm{~g}$ glucose; $0.5 \mathrm{~g} \mathrm{MgSO}_{4} .7 \mathrm{H}_{2} \mathrm{O} ; 0.1 \mathrm{~g} \mathrm{CaCO}_{3} ; 0.006 \mathrm{~g} \mathrm{FeCl}_{3}$; $2.0 \mathrm{~g} \mathrm{Ca}_{3}\left(\mathrm{PO}_{4}\right)_{2} ; 3.0 \mathrm{~g}$ potassium aluminium silicate; and $20.0 \mathrm{~g}$ agar in 11 of deionized sterile water. The $\mathrm{pH}$

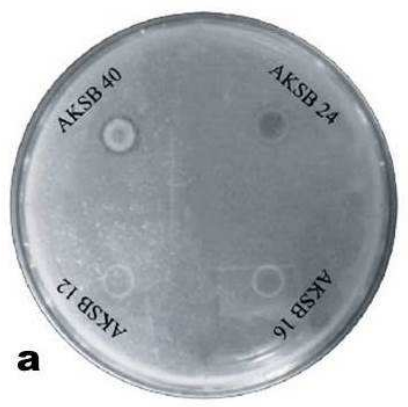

of this medium is adjusted to 7.2 by adding $1 \mathrm{~N} \mathrm{NaOH}$. The plates are incubated at $28 \pm 2{ }^{\circ} \mathrm{C}$ in biological oxygen demand incubator for 3-4 days. The colonies exhibiting clear zones are selected and diameter of the solubilization zone is calculated in $\mathrm{mm}$ and the values are reported as mean \pm standard deviation for each sample. Recently, Rajawat et al. (2016) suggested a modified plate assay for rapid screening of KSB. This assay is based on improved visualization of halo zone formation around the colonies on agar plates, through inclusion of an acid-base indicator dye (bromothymol blue, BTB), to modify the Aleksandrov medium. This assay is also time-saving, more sensitive, and beneficial in comparison to the Aleksandrov plate assay. Comparison of $\mathrm{K}$ solubilization on the Aleksandrov agar plate and modified agar medium plate suggested by Rajawat et $a$. (2016) is shown in Figure 3.

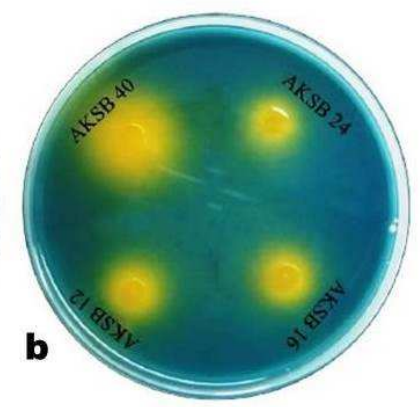

Figure 3. Comparison of K solubilization on the Aleksandrov agar plate (a) and modified agar medium plate (b) after $72 \mathrm{~h}$ of incubation (Rajawat et al., 2016).

Quantitative estimation of $\mathrm{K}$ solubilization is performed by flame photometry or atomic absorption spectrophotometer wherein culture broth is centrifuged and supernatant is used for precipitation of cobalt nitrite. Standard curve for quantification of $\mathrm{K}$ is prepared using various concentrations of $\mathrm{KCl}$ solution (Hu et al., 2006). ). In this assay, mica is usually used as a source of insoluble form of $\mathrm{K}$, although other $\mathrm{K}$ sources were also used in screening KSB (e.g., insoluble magnesium trisilicate, muscovite, illite powder, montmorillonite, kaolinite, potassium-feldspar, biotite, waste mica, bentonite, wood ash, and potassium aluminium silicate) (Meena et al., 2016). In addition, the amount of K solubilization in different culture media (e.g., different $\mathrm{pH}$, temperature, $\mathrm{K}$ source, and carbon source) is different. For example, the amount of $\mathrm{K}$ solubilization by B. edaphicus in the liquid media was more and a better growth was detected on illite than feldspar (Uroz et al., 2009). 
Sugumaran and Janarthanam (2007) reported that the B. mucilaginosus released the $4.29 \mathrm{mg}^{-1} \mathrm{~K}$ in media supplemented with muscovite mica. The amount of $\mathrm{K}$ solubilization by $\mathrm{KSB}$ at $\mathrm{pH}$ 6.5-8.0 was recorded $4.90 \mathrm{mg} \mathrm{l}^{-1}$ (Badr et al., 2006). Bagyalakshmi et al. (2012) studied the ability of K solubilization by Bacillus sp., Burkholderia sp., and Pseudomonas sp. at different temperatures and carbon sources from tea $(\mathrm{Ca}$ mellia sinensis). Among the various types of carbon sources like glucose, fructose, sucrose and starch, the best carbon source for solubilization of $\mathrm{K}$ was found to be glucose at $35^{\circ} \mathrm{C}$ temperature.

In general, the microbial solubilization of $\mathrm{K}$ is strongly influenced by $\mathrm{pH}$, oxygen, the bacterial strains used, and kind of $\mathrm{K}$ bearing minerals; in fact, moderate alkalinity favors the solubilization of silicate (Sheng and Huang, 2001). These studies show that optimal conditions for K solubilization by KSB need to be determined in the future.

\section{Action mechanisms of KSB in solubilizing K}

Currently there is little information available on the mechanisms which by KSB can solubilize K-bearing minerals and release $\mathrm{K}$ for improving the growth and yield of plant. It is generally believed that microorganisms contribute to the release of $\mathrm{K}^{+}$from $\mathrm{K}^{-}$ bearing minerals by several mechanisms. Released $\mathrm{H}^{+}$can directly dissolve the mineral $\mathrm{K}$ as a result of slow releases of exchangeable $\mathrm{K}$, readily available exchangeable $\mathrm{K}$. As occurs in the case of $\mathrm{P}$ solubilization, the major mechanism of $\mathrm{K}$ mineral solubilization is by production the organic and inorganic acids and production of protons (acidolysis mechanism) (Maurya et al., 2014; Meena et al., 2014; Meena et al., 2015b; Parmar and Sindhu, 2013; Sheng et al., 2003; Sheng et al., 2008; Uroz et al., 2009), which are able to convert the insoluble $\mathrm{K}$ (mica, muscovite, and biotite feldspar) to soluble forms of $\mathrm{K}$, easily taking up by the plant (Hu et al., 2006; Meena et al., 2014; Mo and Lian, 2011).

The types of various organic acids such as oxalic acid, tartaric acids, gluconic acid, 2-ketogluconic acid, citric acid, malic acid, succinic acid, lactic acid, propionic acid, glycolic acid, malonic acid, fumaric acid, etc. have been reported in KSB, which are effective in releasing $\mathrm{K}$ from $\mathrm{K}$-bearing minerals ( $\mathrm{Hu}$ et al., 2006; Keshavarz Zarjani et al., 2013; Krishnamurthy, 1989; Liu et al., 2012; Prajapati et al., 2012; Prajapati et al., 2013; Saiyad et al., 2015; Sheng and He, 2006). It has also been known that the type of the organic acid produced by KSB may be different. Among the different organic acids involved in the solubilization of insoluble K, tarteric acid, citric acid, succinic acid, $\alpha$-ketogluconic acid, and oxalic acid are the most prominent acids released by KSB (Meena et al., 2014). Microbial decomposition of organic materials also produces ammonia and hydrogen sulfide that can be oxidized in the soil to form the strong acids such as nitric acid $\left(\mathrm{HNO}_{3}\right)$ and sulfuric acid $\left(\mathrm{H}_{2} \mathrm{SO}_{4}\right)$. Hydrogen ions displace $\mathrm{K}^{+}, \mathrm{Mg}^{2+}, \mathrm{Ca}^{2+}$, and $\mathrm{Mn}^{2+}$ from the cation-exchange complex in a soil (Huang et al., 2013). In addition to decreasing soil $\mathrm{pH}$, organic acids produced by KSB can release of $\mathrm{K}$ ions from the mineral $\mathrm{K}$ by chelating (complex formation) $\mathrm{Si}^{4+}$, $\mathrm{Al}^{3+}, \mathrm{Fe}^{2+}$, and $\mathrm{Ca}^{2+}$ ions associated with $\mathrm{K}$ minerals (Meena et al., 2014; Römheld and Kirkby, 2010; Štyriaková et al., 2003). For example, it was reported that KSB weathered phlogopite via aluminum chelation and acidic dissolution of the crystal network (Abou-el-Seoud and Abdel-Megeed, 2012; Leyval and Berthelin, 1989; Uroz et al., 2009). In addition, The $B$. altitudinis strain could accelerate weathering of potash feldspar, change mineral surface morphology, and induce the formation of new mineral complex. This strain dissolved potash feldspar and significantly released more $\mathrm{Si}, \mathrm{Al}$, and $\mathrm{Fe}$ elements by producing organic acids (Huang et al., 2013). 
Microorganisms including KSB can have a considerable role in proving $\mathrm{K}$ to plant by storing $\mathrm{K}$ in their biomass (a significant quantity of fixed $\mathrm{K}$ ), which is potentially available to plants (Jones et al., 2003). It has been reported that the production of various extracellular polymers (primarily proteins and polysaccharides) can also be led to release of $\mathrm{K}$ from Kbearing minerals for plant uptake (Liu et al., 2006; Shelobolina et al., 2012; Sheng and He, 2006). These substances serve as attachment structures to mineral or rock surface. For example, a study by Welch and Vandevivere (1994) suggested that naturally occurring polymers can affect the mineral dissolution. Solution containing fresh microbial EPS (exopolysaccharides) increases the dissolution rate of feldspars probably by forming complexes with framework ions in solution. KSB also synthesize biofilms, which create controllable microenvironments around microbial cells for weathering (Meena et al., 2014). Biofilm formation on aluminosilicate increases the residence time of water as compared to the residence time at the bare rock or mineral surface and enhances the mineral weathering.

It has been accepted that the microbial biofilms not only accelerated the weathering process but also regulated denudation losses by acting as a protective layer covering the mineral-water-hyphal/root hair interface in the mycorrhizosphere and rhizosphere of vascular plants. Besides, biofilm formation on mineral surface promoted the corrosion of potassium-rich shale and the release of $\mathrm{K}, \mathrm{Si}$ and $\mathrm{Al}$ in the bacteria-mineral contact model (Man et al., 2014). In addition, it is known that the release of organic acids from the plant roots can be effective in enhancing mobilization of mineral $\mathrm{K}$ (Wang et al., 2000). Therefore, it can be suggested that other PGPRs (e.g., IAA-producing bacteria) can also have a role in providing $\mathrm{K}$ for plant by increasing root exudates (Figure 2) (Etesami et al., 2015). In general, the most important mechanisms known in $\mathrm{K}$ mineral solubilization by KSB are "(i) by lowering the $\mathrm{pH}$; (ii) by enhancing chelation of the cations bound to K; and (iii) acidolysis of the surrounding area of microorganism (Meena et al., 2014)”.

\section{Effect of KSB on plant growth and yield}

With the introduction of high yielding crop varieties and the progressive intensification of agriculture, the soils are getting exhausted in $\mathrm{K}$ stock at a faster rate. Inoculation of seeds and seedlings of different plants with KSB generally showed significant enhancement of germination percentage, seedling vigor, plant growth, yield, and $\mathrm{K}$ uptake by plants under greenhouse and field conditions (Anjanadevi et al., 2016; Awasthi et al., 2011; Lynn et al., 2013; Meena et al., 2015a; Meena et al., 2014; Subhashini and Kumar, 2014; Zhang et al., 2013; Zhang and Kong, 2014). For example, Lin et al. (2002) observed $125 \%$ increase in biomass, whereas $\mathrm{K}$ and $\mathrm{P}$ uptake were more than 150 $\%$ in tomato plant due to inoculation of silicate-dissolving bacteria $B$. mucilaginosus strain $\mathrm{RCBC} 13$ as compared to un-inoculated plants. Parmar (2010) showed that inoculation of K-solubilizing isolate HWP47 in wheat (Triticum aestivum L.) var. WH711 caused 51.46 $\%$ increase in root dry weight (RDW) in soil at 60 days after sowing in pots. Similarly, $44.28 \%$ increase in shoot dry weight (SDW) was found in HWP47 inoculated plants. Addition of rock material along with inoculation of HWP47 isolate showed $22.35 \%$ increase in RDW and $73.68 \%$ increase in SDW. Isolates HWP15 and HWP47 also caused significant K uptake in the shoot tissues. Similarly, Badar et al. (2006) reported that application of KSB with K- and P-bearing minerals on sorghum enhanced dry matter yield by $48 \%, 65$ $\%$, and $58 \%$; phosphorus uptake by $71 \%, 110 \%$, and $116 \%$; and $\mathrm{K}$ uptake by $41 \%, 93 \%$, and $79 \%$ in clay, sandy, and calcareous soils, respectively. 
As reported by previous researchers, inoculation with KSB also exerted beneficial effects on growth of cotton and rape (Sheng, 2005), eggplant (Han and Lee, 2005), pepper and cucumber (Han and Lee, 2006; Sangeeth et al., 2012), peanut (Youssef et al., 2010), maize (Abou-el-Seoud and Abdel-Megeed, 2012; Leaungvutiviroj et al., 2010; Singh et al., 2010), sorghum (Badr et al., 2006), wheat (Sheng and He, 2006), Sudan grass (Basak and Biswas, 2012; Basak and Biswas, 2010), sorghum (Badr et al., 2006), tea (Bagyalakshmi et al., 2012), Okra (Prajapati et al., 2013), potato (Abdel-Salam and Shams, 2012), and tomato (Lynn et al., 2013). These studies indicate that the use of KSB as bio-fertilizers for agriculture improvement can reduce the use of agrochemicals and support ecofriendly crop production (Archana et al., 2013; Archana et al., 2012; Prajapati et al., 2013).

\section{Potentialities and challenges of KSB in industry}

$\mathrm{KSB}$ can accelerate weathering reactions of $\mathrm{K}$ minerals; especially when they are in direct contact with mineral surfaces by different action mechanisms. Attempts have been made to use of $\mathrm{K}$ mobilizing bacteria for solubilizing $\mathrm{K}$ from different $\mathrm{K}$ bearing minerals (Meena et al., 2016) and hence to improve plant nutrition. Although KSB could be an alternative and viable technology to solubilize insoluble $\mathrm{K}$ into soluble form, their application in agricultural practice is still prevented by several factors. For example, (i) lack of awareness about bio-fertilizers amongst the farmers; (ii) slow influence of the $\mathrm{K}$ bio-fertilizer on crop yield; (iii) less interest in scientific community on the development of $\mathrm{K}$ bio-fertilizer technologies; (iv) culture collection banks not yet developed for KSB due to the loss of efficient strains developed by scientists; and (v) and deficiency in technology in respect to carrier suitability and product formulations. These are some of the major limitations of the industry, which need to be improved in the near future.

\section{Conclusions and future perspectives}

K-bearing minerals have prominent position in the Earth's crust which can contribute to $\mathrm{K}$ fertilization for crop plants. These plants can only take up $\mathrm{K}$ from the soil solution. Following this uptake, K can be released into soil solution from insoluble minerals but it is generally small in comparison to the plant requirement, because the concentration of soluble $\mathrm{K}$ in the soil solution is very low, and $\mathrm{K}$ is relatively immobile in the soil. Therefore, to meet plant requirements, $\mathrm{K}$ fertilizers should be applied, which are a contemporary practice to supply available $\mathrm{K}$ in extensive agricultural systems (Yadegari and Mosadeghzad, 2012; Zhang et al., 2013). However, these fertilizers are costly and long-term use of which results in the increase of the cost of inputs, the decrease of the agricultural profitability, and a large number of environmental problems due to having heavy metals accumulating in soil and plant system. These toxic chemicals are able to find their way into the fruits and vegetables, and ultimately human body (Hu et al., 2010; Tuli et al., 2010).

It is well known that the application of KSB can be a promising technique to solubilize the $\mathrm{K}$ reserves from soil and make it available to the plants, resulting in promotion of plant growth and minimizing the application of K-fertilizers. K solubilization is carried out by a large number of bacteria such as $B$. mucilaginosus, B. edaphicus, B. circulans, Pseudomonas, Burkholderia, Acidithiobacillus ferrooxidans, and Paenibacillus spp. Previous researches well showed that KSB were able to dissolve $\mathrm{K}$ from different insoluble $\mathrm{K}$ bearing minerals by excreting organic acids. Among action mechanisms of KSB in making $\mathrm{K}$ available to plant, production of organic acids is major mechanism, which can either directly increase dissolution either by a proton- or ligand-mediated mechanism or they can also indirectly increase dissolution by the formation of complexes in solution with 
reaction products. Therefore, application of KSB as biofertilizer not only enhance plant growth and yield but also can lessen the use of agrochemicals and support eco-friendly crop production. These technologies are becoming vital in modern day agricultural practices. The changing scenario of agricultural practices and environmental hazards associated with chemical fertilizers demands more significant role of biofertilizers in coming years.

Based on the knowledge generated up to now, we suggest several future avenues of research approaches: (i) KSB have been rarely studied under field conditions. Most of these studies were carried out in the laboratory and little information is available on the field application of such methods, which is most likely due to difficulties in soil inoculation under field conditions (Parmar and Sindhu, 2013; Prajapati et al., 2013; Raj et al., 2004; Sheng and He, 2006; Sugumaran and Janarthanam, 2007). It is well known that the results obtained in a greenhouse or under in vitro conditions may differ from field results. Therefore, further field studies should be performed to assess the potential of such techniques for agricultural production systems and also evaluate their impacts on crop growth and soil behavior; (ii) study of role of KSB in increased availability of other nutrients (nutrients that their availability is affected by $\mathrm{pH}$ ) as $\mathrm{P}, \mathrm{N}, \mathrm{Fe}, \mathrm{Zn}$, etc.; (iii) study of the effect of other PGPRs such as IAA producers, ACC deaminase producers, phosphate solubilizers, and N2 fixers on the availability of K; (iv) study of interactions (positive or negative) of between KSB with other PGPRs in the availability of K; (v) determination of the optimal conditions for KSB activity such as organic matter, etc.; (vi) evaluation of plant species effective in $\mathrm{K}$ uptake and $\mathrm{K}$ solubilizing microbial populations. Understanding the mechanisms of $\mathrm{KSB}$ is important in order to decide what type of bacteria is better to use with which plant in a given situation. Therefore, the effect of KSB on different plants in different geographic regions should be studied; (vii) study of the stability of inoculant in the soil and evaluation of soil mineralogical properties before being performed inoculation; and (viii) compared to other PGPRs, there is little information on molecular biology of KSB that needs to be further studied in the future.

Taken together, well-designed, large-scale and longterm field trials are required to evaluate the feasibility of KSB application in increasing the availability of K and other nutrients and economic feasibility of different $\mathrm{K}$ sources should also be investigated.

\section{Acknowledgements}

We wish to thank University of Tehran for providing the necessary facilities for this study.

\section{References}

Abdel-Salam, M.A., Shams, A.S. 2012. Feldspar-K fertilization of potato (Solanum tuberosum L.) augmented by biofertilizer. J. Agric. Environ. Sci. 12, 694-699.

Abou-el-Seoud, I., Abdel-Megeed, A. 2012. Impact of rock materials and biofertilizations on $\mathrm{P}$ and $\mathrm{K}$ availability for maize (Zea Maize) under calcareous soil conditions. Saudi J. Biol. Sci. 19, 55-63.

Adesemoye, A.O., Kloepper, J.W. 2009. Plant-microbes interactions in enhanced fertilizer-use efficiency. Appl. Microbiol. Biotechnol. 85, 1-12.

Ahmad, M., Nadeem, S.M., Naveed, M., Zahir, Z.A. 2016. Potassium-solubilizing bacteria and their application in agriculture, in: Meena, V.S., Maurya, B.R., Verma, J.P., Meena, R.S. (Eds.), Potassium solubilizing microorganisms for sustainable agriculture. Springer India, New Delhi, pp. 293-313. 
Almeida, H.J., Pancelli, M.A., Prado, R.M., Cavalcante, V.S., Cruz, F.J.R. 2015. Effect of potassium on nutritional status and productivity of peanuts in succession with sugar cane. J. Soil Sci. Plant Nutr. 15, 1-10.

Anjanadevi, I.P., John, N.S., John, K.S., Jeeva, M.L., Misra, R.S. 2016. Rock inhabiting potassium solubilizing bacteria from Kerala, India: characterization and possibility in chemical $\mathrm{K}$ fertilizer substitution. J. Basic Microbiol. 56, 67-77.

Archana, D., Nandish, M., Savalagi, V., Alagawadi, A. 2013. Characterization of potassium solubilizing bacteria (KSB) from rhizosphere soil. BIOINFOLET-A Quarterly J. Life Sci. 10, 248-257.

Archana, D.S., Nandish, M.S., Savalagi, V.P., Alagawadi, A.R. 2012. Screening of potassium solubilizing bacteria (KSB) for plant growth promotional activity. BIOINFOLET-A Quarterly J. Life Sci. 9, 627-630.

Awasthi, R., Tewari, R., Nayyar, H. 2011. Synergy between plants and P-solubilizing microbes in soils: effects on growth and physiology of crops. Int. Res. J. Microbiol. 2, 484-503.

Badr, M.A., Shafei, A.M., Sharaf El-Deen, S.H. 2006. The dissolution of $\mathrm{K}$ and P-bearing minerals by silicate dissolving bacteria and their effect on sorghum growth. Res. J. Agri. Biol. Sci. 2, 5-11.

Bagyalakshmi, B., Ponmurugan, P., Balamurugan, A. 2012. Impact of different temperature, carbon and nitrogen sources on solubilization efficiency of native potassium solubilizing bacteria from tea (Camellia sinensis). J. Biol. Res. 3, 36-42.

Bakhshandeh, E., Pirdashti, H., Lendeh, K.S. 2017. Phosphate and potassium-solubilizing bacteria effect on the growth of rice. Ecol. Eng. 103, 164169.

Basak, B., Biswas, D. 2012. Modification of waste mica for alternative source of potassium: evaluation of potassium release in soil from waste mica treated with potassium solubilizing bacteria (KSB). LAP LAMBERT Academic Publishing.

Basak, B.B., Biswas, D.R. 2010. Co-inoculation of potassium solubilizing and nitrogen fixing bacteria on solubilization of waste mica and their effect on growth promotion and nutrient acquisition by a forage crop. Biol. Fertil. Soil. 46, 641648.

Bhattacharya, S., Bachani, P., Jain, D., Patidar, S.K., Mishra, S., 2016. Extraction of potassium from $\mathrm{K}$-feldspar through potassium solubilization in the halophilic Acinetobacter soli (MTCC 5918) isolated from the experimental salt farm. Int. J. Min. Proc. 152, 53-57.

Cecílio Filho, A.B., Feltrim, A.L., Mendoza Cortez, J.W., Gonsalves, M.V., Pavani, L.C., Barbosa, J.C. 2015. Nitrogen and potassium application by fertigation at different watermelon planting densities. J. Soil Sci. Plant Nutr. 15, 928-937.

Chaparro, J.M., Badri, D.V., Bakker, M.G., Sugiyama, A., Manter, D.K., Vivanco, J.M. 2013. Root exudation of phytochemicals in Arabidopsis follows specific patterns that are developmentally programmed and correlate with soil microbial functions. PloS one. 8, e55731.

Cheng, Z., McConkey, B.J., Glick, B.R. 2010. Proteomic studies of plant-bacterial interactions. Soil Biol. Biochem. 42, 1673-1684.

de Zelicourt, A., Al-Yousif, M., Hirt, H. 2013. Rhizosphere microbes as essential partners for plant stress tolerance. Molecular Plant. 6, 242-245.

Etesami, H., Alikhani, H.A., Hosseini, H.M. 2015. Indole-3-acetic acid and 1-aminocyclopropane1-carboxylate deaminase: Bacterial traits required in rhizosphere, rhizoplane and/or endophytic competence by beneficial bacteria, Bacterial metabolites in sustainable agroecosystem. Springer, pp. 183-258. 
Gallegos-Cedillo, V.M., Urrestarazu, M., Álvaro, J.E. 2016. Influence of salinity on transport of Nitrates and Potassium by means of the xylem sap content between roots and shoots in young tomato plants. J. Soil Sci. Plant Nutr. 16 (4), 991-998

Glick, B.R. 2012. Plant Growth-Promoting Bacteria: Mechanisms and Applications. Scientifica. 2012, 963401.

Gundala, P.B., Chinthala, P., Sreenivasulu, B. 2013. A new facultative alkaliphilic, potassium solubilizing, Bacillus Sp. SVUNM9 isolated from mica cores of Nellore District, Andhra Pradesh, India. Research and Reviews. J. Microbiol. Biotechnol. 2, 1-7.

Han, H.-S., Lee, K.D. 2006. Effect of co-inoculation with phosphate and potassium solubilizing bacteria on mineral uptake and growth of pepper and cucumber. Plant soil Environ. 52, 130.

Han, H.S., Lee, K.D. 2005. Phosphate and potassium solubilizing bacteria effect on mineral uptake, soil availability and growth of eggplant. Res. J. Agric. Biol. Sci. 1, 176-180.

Haub, C., Gribble, J., Jacobsen, L. 2012. World Population Data Sheet 2012. Population Reference Bureau, Washington.

Hu, G., Huang, S., Chen, H., Wang, F. 2010. Binding of four heavy metals to hemicelluloses from rice bran. Food Res. International. 43, 203-206.

Hu, X., Chen, J., Guo, J. 2006. Two phosphate-and potassium-solubilizing bacteria isolated from Tianmu Mountain, Zhejiang, China. World j. Microbiol. Biotechnol. 22, 983-990.

Huang, Z., He, L., Sheng, X., He, Z. 2013. Weathering of potash feldspar by Bacillus sp. L11. Wei sheng wu xue bao. Acta Microbiol. Sinica. 53, 1172-1178.

Hussain, Z., Khattak, R.A., Irshad, M., Mahmood, Q., An, P. 2016. Effect of saline irrigation water on the leachability of salts, growth and chemical composition of wheat (Triticum aestivum L.) in saline-sodic soil supplemented with phosphorus and potassium. J. soil Sci. Plant Nutr. 16, 604-620.

Jones, D.L., Dennis, P.G., Owen, A.G., Van Hees, P.A.W. 2003. Organic acid behavior in soils-misconceptions and knowledge gaps. Plant soil. 248, 31-41.

Keshavarz Zarjani, J., Aliasgharzad, N., Oustan, S., Emadi, M., Ahmadi, A. 2013. Isolation and characterization of potassium solubilizing bacteria in some Iranian soils. Arch. Agron. Soil Sci. 59, 1713-1723.

Krishnamurthy, H.A. 1989. Effect of pesticides on phosphate solubilizing microorganisms, $\mathrm{M}$. Sc.(Agric.) thesis, University of Agricultural Sciences, Dharwad.

Leaungvutiviroj, C., Ruangphisarn, P., Hansanimitkul, P., Shinkawa, H., Sasaki, K. 2010. Development of a new biofertilizer with a high capacity for N2 fixation, phosphate and potassium solubilization and auxin production. Biosci. Biotechnol. Biochem. 74, 1098-1101.

Leyval, C., Berthelin, J. 1989. Interactions between Laccaria laccata, Agrobacterium radiobacter and beech roots: Influence on $\mathrm{P}, \mathrm{K}, \mathrm{Mg}$, and Fe mobilization from minerals and plant growth. Plant Soil. 117, 103-110.

Liu, D., Lian, B., Dong, H. 2012. Isolation of Paenibacillus sp. and assessment of its potential for enhancing mineral weathering. Geomicrobiol. J. 29, 413-421.

Liu, W., Xu, X., Wu, X., Yang, Q., Luo, Y., Christie, P. 2006. Decomposition of silicate minerals by Bacillus mucilaginosus in liquid culture. Environ. Geochem. health. 28, 133-140.

Lynn, T.M., Win, H.S., Kyaw, E.P., Latt, Z.K., Yu, S.S. 2013. Characterization of phosphate solubilizing and potassium decomposing strains and 
study on their effects on tomato cultivation. Int. J. Innov. Applied Stud. 3, 959-966.

Ma, Y., Oliveira, R.S., Freitas, H., Zhang, C. 2016. Biochemical and molecular mechanisms of plantmicrobe-metal interactions: relevance for phytoremediation. Front. Plant Sci.7.

Man, L.Y., Cao, X.Y., Sun, D.S. 2014. Effect of potassium-solubilizing bacteria-mineral contact mode on decomposition behavior of potassium-rich shale. Chin. J. Nonferrous Met. 24, 48-52.

Maurya, B.R., Meena, V.S., Meena, O.P. 2014. Influence of Inceptisol and Alfisol's potassium solubilizing bacteria (KSB) isolates on release of $\mathrm{K}$ from Waste mica. Vegetos. 27, 181-187.

Meena, V.S., Maurya, B.R., Bahadur, I. 2015a. Potassium solubilization by bacterial strain in waste mica. Bangladesh J. Bot. 43, 235-237.

Meena, V.S., Maurya, B.R., Verma, J.P. 2014. Does a rhizospheric microorganism enhance $\mathrm{K}^{+}$availability in agricultural soils?. Microbiol. Res. 169, 337-347.

Meena, V.S., Maurya, B.R., Verma, J.P., Aeron, A., Kumar, A., Kim, K., Bajpai, V.K. 2015b. Potassium solubilizing rhizobacteria (KSR): Isolation, identification, and K-release dynamics from waste mica. Ecol. Eng. 81, 340-347.

Meena, V.S., Maurya, B.R., Verma, J.P., Meena, R.S. 2016. Potassium solubilizing microorganisms for sustainable agriculture. Springer.

Mo, B., Lian, B. 2011. Interactions between Bacillus mucilaginosus and silicate minerals (weathered adamellite and feldspar): Weathering rate, products, and reaction mechanisms. Chinese J. Geochem. 30, 187-192.

Padma, S.D., Sukumar, J. 2015. Response of mulberry to inoculation of potash mobilizing bacterial isolate and other bio-inoculants. Global J. Bio. Sci. Biotechnol. 4 50-53.
Parmar, P., Sindhu, S.S. 2013. Potassium solubilization by rhizosphere bacteria: influence of nutritional and environmental conditions. J. Microbiol. Res. 3, 25-31.

Prajapati, K., Sharma, M., Modi, H. 2012. Isolation of two potassium solubilizing fungi from ceramic industry soils. Life Sci. Leaflets. 5, 71-75.

Prajapati, K., Sharma, M.C., Modi, H.A. 2013. Growth promoting effect of potassium solubilizing microorganisms on okra (Abelmoscus Esculantus). Int. J. Agri. Sci. Res. (IJASR). 1, 181-188.

Raj, S.A., Kannaiyan, S., Kumar, K., Govindarajan, K. 2004. Solubilization of silicate and concurrent release of phosphorus and potassium in rice ecosystem. Biofertilizers technology for rice based cropping system. 372-378.

Rajawat, M.V.S., Singh, S., Tyagi, S.P., Saxena, A.K. 2016. A Modified Plate Assay for Rapid Screening of Potassium-Solubilizing Bacteria. Pedosphere. 26, 768-773.

Römheld, V., Kirkby, E.A. 2010. Research on potassium in agriculture: needs and prospects. Plant Soil. 335, 155-180.

Saha, M., Maurya, B.R., Meena, V.S., Bahadur, I., Kumar, A. 2016. Identification and characterization of potassium solubilizing bacteria (KSB) from Indo-Gangetic Plains of India. Biocatal. Agri. Biotechnol. 7, 202-209.

Saiyad, S.A., Jhala, Y.K., Vyas, R.V. 2015. Comparative efficiency of five potash and phosphate solubilizing bacteria and their key enzymes useful for enhancing and improvement of soil fertility. International J. Sci. Res. Publications. 5, 1-6.

Sangeeth, K.P., Bhai, R.S., Srinivasan, V. 2012. Paenibacillus glucanolyticus, a promising potassium solubilizing bacterium isolated from black pepper (Piper nigrum L.) rhizosphere. J. Spic. Aromatic. Crop. 21. 
Shelobolina, E., Xu, H., Konishi, H., Kukkadapu, R., Wu, T., Blöthe, M., Roden, E. 2012. Microbial lithotrophic oxidation of structural Fe (II) in biotite. Appl. Environ. Microbiol. 78, 5746-5752.

Sheng, X.F., Xia, J.J., Chen, J. 2003. Mutagenesis of the Bacillus edaphicus strain NBT and its effect on growth of chili and cotton. Agri. Sci. China 2, 409-412.

Sheng, X. 2005. Growth promotion and increased potassium uptake of cotton and rape by a potassium releasing strain of Bacillus edaphicus. Soil Biol. Biochem. 37, 1918-1922.

Sheng, X., Huang, W. 2001. Mechanism of potassium release from feldspar affected by the sprain $\mathrm{Nbt}$ of silicate bacterium. Acta Pedologica Sinica. 39, 863-871.

Sheng, X.F., He, L.Y. 2006. Solubilization of potassium-bearing minerals by a wild-type strain of Bacillus edaphicus and its mutants and increased potassium uptake by wheat. Can. J. Microbiol. 52, 66-72.

Sheng, X.F., Zhao, F., He, L.Y., Qiu, G., Chen, L. 2008. Isolation and characterization of silicate mineral-solubilizing Bacillus globisporus Q12 from the surfaces of weathered feldspar. Can. J. Microbiol. 54, 1064-1068.

Singh, G., Biswas, D.R., Marwaha, T.S. 2010. Mobilization of potassium from waste mica by plant growth promoting rhizobacteria and its assimilation by maize (Zea mays) and wheat (Triticum aestivum L.): a hydroponics study under phytotron growth chamber. J. Plant Nutr. 33, 12361251 .

Sparks, D.L., 1987. Potassium dynamics in soils, Advances in Soil Science. Springer, pp. 1-63.

Sparks, D.L., Huang, P.M. 1985. Physical chemistry of soil potassium. Potassium in agriculture. 201276.
Štyriaková, I., Štyriak, I., Galko, D., Hradil, P., Bezdička, P. 2003. The release of iron-bearing minerals and dissolution of feldspars by heterotrophic bacteria of Bacillus species. Ceram. Silik. 47, 20-26.

Subhashini, D.V., Kumar, A. 2014. Phosphate solubilising Streptomyces spp obtained from the rhizosphere of Ceriops decandra of Corangi mangroves. The Indian J. Agri. Sci. 84.

Sugumaran, P., Janarthanam, B. 2007. Solubilization of potassium containing minerals by bacteria and their effect on plant growth. World J. Agri. Sci. 3, 350-355.

Tuli, R., Chakrabarty, D., Trivedi, P.K., Tripathi, R.D. 2010. Recent advances in arsenic accumulation and metabolism in rice. Mole. Breeding. 26, 307323.

Uroz, S., Calvaruso, C., Turpault, M.-P., Frey-Klett, P. 2009. Mineral weathering by bacteria: ecology, actors and mechanisms. Trends Microbiol. 17, 378-387.

Wang, J.G., Zhang, F.S., Zhang, X.L., Cao, Y.P. 2000. Release of potassium from K-bearing minerals: effect of plant roots under P deficiency. Nutr. Cycl. Agroecosys. 56, 45-52.

Welch, S.A., Vandevivere, P. 1994. Effect of microbial and other naturally occurring polymers on mineral dissolution. Geomicrobiol. J. 12, 227-238.

White, P.J., Karley, A.J. 2010. Potassium, Plant Cell Monographs, pp. 199-224.

Xiao, Y., Wang, X., Chen, W., Huang, Q. 2017. Isolation and identification of three potassium-solubilizing bacteria from rape rhizospheric soil and their effects on ryegrass. Geomicrobiol. J. 1-8.

Yadegari, M., Mosadeghzad, Z. 2012. Biofertilizers effects on quantitative and qualitative yield of Thyme (Thymus vulgaris). Afr. J. Agri. Res. 7, 4716-4723. 
Yang, B.M., Yao, L.X., Li, G.L., He, Z.H., Zhou, C.M. 2015. Dynamic changes of nutrition in litchi foliar and effects of potassium-nitrogen fertilization ratio. J. Soil Sci. Plant Nutr. 15, 98-110.

Youssef, G.H., Seddik, W.M.A., Osman, M.A. 2010. Efficiency of natural minerals in presence of different nitrogen forms and potassium dissolving bacteria on peanut and sesame yields. J. Am. Sci. 6, 647-660.

Zeng, X., Liu, X., Tang, J., Hu, S., Jiang, P., Li, W., $\mathrm{Xu}, \mathrm{L}$. 2012. Characterization and potassium-solubilizing ability of Bacillus Circulans Z 1-3. Adv. Sci. Lett. 10, 173-176.
Zhang, A., Zhao, G., Gao, T., Wang, W., Li, J., Zhang, S., Zhu, B. 2013. Solubilization of insoluble potassium and phosphate by Paenibacillus kribensis CX-7: a soil microorganism with biological control potential. Afri. J. Microbiol. Res. 7, 41-47.

Zhang, C., Kong, F. 2014. Isolation and identification of potassium-solubilizing bacteria from tobacco rhizospheric soil and their effect on tobacco plants. Appl.Soil. Ecol. 82, 18-25.

Zhao, S., Li, K., Zhou, W., Qiu, S., Huang, S., He, P. 2016. Changes in soil microbial community, enzyme activities and organic matter fractions under long-term straw return in north-central China. Agri. Ecos. Environ. 216, 82-88. 